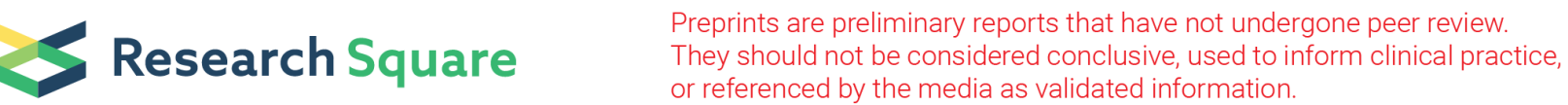

\section{Prevalence of Entamoeba histolytica and Giardia lamblia among schoolchildren in Um-Asher Area, Sudan}

Khalid Hajissa ( $\sim$ khalid541983@yahoo.com )

Omdurman Islamic University https://orcid.org/0000-0002-1725-6702

Abd Elhafiz M.A. Muhajir

Omdurman Islamic University

Tmador Abd All

Omdurman Islamic University

M.S. Zakeia

Omdurman Islamic University

Hamza Adam Eshag

Omdurman Islamic University

Elfadel Elnzer

Omdurman Islamic University

Elkhatieb Nahied

Omdurman Islamic University

Muhamed Jafer

Weaad Medical Center, Khartoum

Abdulwali Sabo

Universiti Sains Malaysia

Zeehaida Mohamed

Department of medical Microbioloy \& Parasitology, School of Medical Sciences, Universiti Sains Malaysia

\section{Research note}

Keywords: Prevalence, Intestinal parasites, Entamoeba histolytica, Giardia lamblia, schoolchildren, Sudan

Posted Date: August 28th, 2020

DOI: https://doi.org/10.21203/rs.3.rs-61761/v1

License: (c) (1) This work is licensed under a Creative Commons Attribution 4.0 International License.

Read Full License 


\section{Abstract}

Objective: Infections with Entamoeba histolytica and Giardia lamblia are widely prevalent and responsible for serious public health issues among school-aged children in developing countries. This study was conducted to determine the prevalence of these parasites among children from two primary schools in Um-Asher area, Khartoum, Sudan. A total 170 fresh stool specimens were collected from November 2017 to June 2018. The samples were examined by microscopy for the presence of the two parasites.

Results: The overall prevalence of both parasites among the 170 children was $20 \%$, with 13 children infected with E. histolytica (7.6\%) and 23 with G. lamblia (13.5\%). Most of the positive cases were single infections. Only two children (1.2\%) had mixed infections. This indicates that these gastrointestinal parasites remain a challenging public health concern wherever sanitation and health measures are limited.

\section{Introduction}

Intestinal parasites are a serious medical problem that significantly affects public health and results in considerable morbidity and mortality in developing countries (1), including Sudan $(2,3)$, where many conditions, including climatic, ecological, socioeconomic and hygienic, favour their transmission. In addition, infection with these pathogenic parasites can be associated with gastrointestinal diseases and malnutrition, particularly among young children (4). Several pathogenic intestinal parasites may be responsible for the above health problems, two parasites, Entamoeba histolytica (E. histolytica) and Giardia lamblia ( $G$. lamblia) being the commonest and have been reported and associated with significant illnesses in developing countries. E. histolytica, the etiologic agent of amoebiasis, is an important parasite of the human gut. Among parasitic diseases, amoebiasis is considered the third most common cause of death after malaria and schistosomiasis (5). The parasite causes amoebic dysentery, amoebic colitis and amoebic liver abscess and leads to almost 100 thousand deaths annually (6). $G$. lamblia is another common cause of gastrointestinal diseases in humans throughout the world, and approximately $5-10 \%$ of the global population is at risk of giardiasis, which is considered one of the main nonviral causes of diarrhoeal diseases in humans (7).

In Sudan, the two parasites are widely distributed and pose significant challenges to health authorities due to insufficient health education, poor sanitation and improper disposal of human excreta, which lead to the contamination of food and drinking water, and poverty $(1,8)$. In this regard, Sudanese children are at risk of infection (9); the infection rate of Entamoeba spp. is predicted to increase. Meanwhile, schoolchildren are the primary victims of Giardia spp. infection in both developed and developing countries. Accordingly, prevalence surveys of both parasites are a prerequisite for developing effective control strategies. However, only few studies have been conducted in different parts of Sudan and mostly among schoolchildren. Therefore, this study was conducted to determine the prevalence of E. histolytica 
and G. lamblia and the associated risk factors among schoolchildren from Um-Asher area, South Khartoum, Sudan.

\section{Methodology}

\section{Study area, period and study subjects}

A cross-sectional study conducted in Um-Asher (Al Kalakla) area, from November 2017 until June 2018. Um-Asher is located at the latitude of $15^{\circ} 28^{\prime} 04 \rrbracket \mathrm{N}$ and longitude of $32^{\circ} 29^{\prime} 08 \otimes \mathrm{E}$, a height of $384 \mathrm{~m}$ and $16.3 \mathrm{~km}$ south of Khartoum, Sudan. Convenience sampling method was used to enrol children aged between 6 and 17 years who were attending the selected primary schools. Any children who were taking medication for amoebiasis or giardiasis within the three weeks of data collection were excluded. Accordingly, 170 primary schoolchildren (75 males and 95 were females) were selected and enrolled.

\section{Sample collection and examination}

Approximately $5-7 \mathrm{~g}$ of fresh stool specimens were collected in sterile, carefully labelled plastic containers. The stool sample was added with $10 \%$ formaldehyde as preservative. The stool specimens were individually inspected for the presence of mucous or blood and consistency. The detection of $E$. histolytica and G. lamblia infections was carried out using direct faecal smears in normal saline. All patient details including socio-demographic characteristics and associated risk factors were obtained via previously developed standardised questionnaire (10).

\section{Statistical analysis}

SPSS 24.0 was used to conduct the descriptive and logistic regression analyses. The descriptive data were presented as frequencies and percentages. Simple and multiple logistic regression analyses were performed to identify variables associated with the positive outcome of E. histolytica and G. lamblia. In the simple logistic regression analysis, the variables with a $p$-value $<0.25$ were considered important and therefore included in the multiple logistic regression analysis. The final model was assessed for fitness by using the receiver operating characteristics (ROC) curve, the Hosmer and Lemeshow test, the classification table, interaction between the study variables and multicollinearity.

\section{Results}

\section{Socio-demographic characteristics of study participants}

A total of 170 students from two primary schools were involved. The majority of the participants $(68.2 \%)$ were between the age of 10 and 13 years. Amongst the study participants, 33.5\% $(n=57)$ were residing less than $1 \mathrm{~km}$ from a water source, and $66.5 \%(n=113)$ were residing more than $1 \mathrm{~km}$ away from a water source. The main source of water was tap water $94.7 \%(n=161)$. The majority of the participants $(61.8 \%, n=105)$ had no sanitary latrine. The summary of all the participant's characteristics is presented in Table 1. 
Table 1

Socio-demographic characteristics of participants $(n=170)$

\begin{tabular}{|c|c|c|c|}
\hline Variables & Categories & Frequency & Percent \\
\hline \multirow[t]{2}{*}{ Gender } & Male & 75 & 44.1 \\
\hline & Female & 95 & 55.9 \\
\hline \multirow[t]{2}{*}{ Age } & $6-9$ & 38 & 22.4 \\
\hline & More than 10 & 132 & 77.6 \\
\hline \multirow[t]{2}{*}{ Distance of residence from water source } & $<1 \mathrm{Km}$ & 57 & 33.5 \\
\hline & $>1 \mathrm{Km}$ & 113 & 66.5 \\
\hline \multirow[t]{2}{*}{ Source of Drinking water } & Ground/ Pure Water & 9 & 5.3 \\
\hline & Tap water & 161 & 94.7 \\
\hline \multirow[t]{2}{*}{ Type of latrine } & Non Sanitary Latrine & 105 & 61.8 \\
\hline & Sanitary latrine & 65 & 38.2 \\
\hline \multirow[t]{3}{*}{ Washing cloth } & In the house & 165 & 97.1 \\
\hline & In the river & 2 & 1.2 \\
\hline & Other & 3 & 1.8 \\
\hline \multirow[t]{2}{*}{ Hand washing before meals } & No & 109 & 64.1 \\
\hline & Yes & 61 & 35.9 \\
\hline \multirow[t]{2}{*}{ Habit of washing vegetables and fruits } & No & 9 & 5.3 \\
\hline & Yes & 161 & 94.7 \\
\hline \multirow[t]{2}{*}{ breakfast } & In the house & 63 & 37.1 \\
\hline & In the school & 107 & 62.9 \\
\hline \multirow[t]{4}{*}{ Bathing habit } & Home & 151 & 88.8 \\
\hline & Canal & 3 & 1.8 \\
\hline & River & 3 & 1.8 \\
\hline & All & 13 & 7.6 \\
\hline \multirow[t]{2}{*}{ Frequency of Trimming finger nail } & Once a week & 100 & 58.8 \\
\hline & More than one week & 70 & 41.2 \\
\hline \multirow[t]{2}{*}{ E. Histolytica } & Negative & 157 & 92.4 \\
\hline & Positive & 13 & 7.6 \\
\hline
\end{tabular}




\begin{tabular}{|llll|}
\hline Variables & Categories & Frequency & Percent \\
\hline G. lamblia & Negative & 147 & 86.5 \\
\cline { 2 - 4 } & Positive & 23 & 13.5 \\
Residency during school holiday & Outside the area & 84 & 49.4 \\
& In the area & 86 & 50.6 \\
\hline
\end{tabular}

\section{Prevalence of E. histolytica infection and its associated risk factors}

Microscopic analysis showed that only 13 (7.6\%) were found positive for E. histolytica. In the simple logistic regression analysis, three variables, namely: gender, latrine type, and breakfast had an unadjusted crude odds ratio (COR) with p-values less than 0.25 (Table 2). Male were 3.1 times more likely to test positive for $E$. histolytica than female children $(\mathrm{COR}=3.10$, $\mathrm{p}$-value $=0.069)$. The subjects who ate breakfast in the school were 7.8 times more likely to test positive than those who took breakfast at home $(\mathrm{COR}=7.83$, $\mathrm{p}$-value $=0.051)$. Furthermore, subjects with no sanitary latrine were $64 \%$ less likely to test positive than those with sanitary latrine $(C O R=0.36, p$-value $=0.082)$. The forward $L R$ and backward $L R$ selection method was used in the multiple logistic regression analysis. All the three variables (gender, type of latrine and breakfast) were selected and run using the enter method. Male were 3.5 times more likely to test positive than female, with adjusted odds ratio $(A O R)=3.50$ and $p$-value $=0.052$. Subjects who took their breakfast in school were 9.5 times more likely to test positive than those who ate breakfast at home $(A O R=9.50$, $p$-value $=0.035)$. Those with no sanitary latrine were $71 \%$ less likely to test positive than those with sanitary latrine $(A O R=0.29, p$-value $=0.043)$. 


\section{Characteristics}

$\begin{array}{llllll}\begin{array}{l}\text { Negative No. } \\ (\%)\end{array} & \begin{array}{l}\text { Positive No. } \\ (\%)\end{array} & \begin{array}{l}\text { Crude OR } \\ (95 \% \mathrm{Cl})\end{array} & \begin{array}{l}\text { P } \\ \text { value }\end{array} & \begin{array}{l}\text { Adjusted } \\ \text { OR }\end{array} & \text { P }\end{array}$

\section{Gender}

Female

$91(95.8)$

$4(4.2)$

1

1

Male

$66(88.0)$

$9(12.0)$

$3.10(0.92$ 10.51)

0.069

$3.50(0.99$, 12.39)

0.052

\section{Age}

6-9

$36(94.7)$

2 (5.3)

1

More than 10

$121(91.7)$

$11(8.3)$

$1.64(0.35$

7.72)

0.534

\section{Distance of residence from water source}

$\begin{array}{lllll}<1 \mathrm{Km} & 54(94.7) & 3(5.3) & 1 & \\ >1 \mathrm{Km} & 103(91.2) & 10(8.8) & \begin{array}{l}1.75(0.46, \\ 6.62)\end{array} & 0.411\end{array}$

\section{Type of latrine}

Non Sanitary

Latrine

$$
100(95.2)
$$

$5(4.8)$

$0.36(0.11$

1.14)

0.082

$0.29(0.08$

0.043

Sanitary latrine

57 (87.7)

$8(12.3)$

1

\section{Hand washing before meals}

$\begin{array}{lllll}\text { No } & 100(91.7) & 9(8.3) & 1 & \\ \text { Yes } & 57(93.4) & 4(6.6) & \begin{array}{l}0.78(0.23, \\ 2.65)\end{array} & 0.690\end{array}$

Habit of washing vegetables and fruits

\begin{tabular}{lllllll} 
No & $8(88.9)$ & $1(11.1)$ & $\begin{array}{l}1.55(0.18, \\
13.5)\end{array}$ & 0.690 & \\
Yes & $149(92.5)$ & $12(7.5)$ & 1 & & \\
Breakfast & & & & & & \\
In the house & $62(98.4)$ & $1(1.6)$ & 1 & & 1 & \\
\hline In the school & $95(88.8)$ & $12(11.2)$ & $\begin{array}{l}7.83(0.99, \\
61.75)\end{array}$ & 0.051 & $\begin{array}{l}9.50(1.17, \\
77.16)\end{array}$ & 0.035 \\
& & & & &
\end{tabular}




\section{Characteristics}

$\begin{array}{llllll}\begin{array}{l}\text { Negative No. } \\ (\%)\end{array} & \begin{array}{l}\text { Positive No. } \\ (\%)\end{array} & \begin{array}{l}\text { Crude OR } \\ (95 \% \mathrm{Cl})\end{array} & \begin{array}{l}\text { P } \\ \text { value }\end{array} & \begin{array}{l}\text { Adjusted } \\ \text { OR }\end{array} & \text { P }\end{array}$

\section{Frequency of Trimming finger nail}

$\begin{array}{lllll}\text { Once a week } & 92(92.0) & 8(8.0) & 1 & \\ \begin{array}{llll}\text { Moe than once a } \\ \text { week }\end{array} & 65(92.9) & 5(7.1) & \begin{array}{l}0.89(0.28, \\ 2.83)\end{array} & 0.885 \\ \end{array}$

No significant interaction was found between all the pairs of variables tested ( $p$-values $>0.05$ ). No multicollinearity for all the variables $(\mathrm{VIF}<10)$ was observed. The assumption for the Hosmer and Lemeshow test was satisfied ( $p$-value $=0.961)$, indicating adequate model fitness with the three variables. The area under the ROC curve (AUC) was $79.5 \%$, indicating the sufficient discriminant ability of the final model with gender, type of latrine and place of breakfast.

\section{Prevalence of $\mathbf{G}$. lamblia infection and its associated risk factors}

A total of 23 children (13.5\%) were found to be infected with G. lamblia. In simple logistic regression analysis, three variables, namely: age, bathing habit, and frequency of trimming had an unadjusted COR with $p$-values less than 0.25 , (Table 3 ). Children aged more than 10 years were $52 \%$ less likely to be diagnosed positive for $G$. lamblia than those aged $6-9$ years $(C O R=0.48$, p-value $=0.130)$. For bathing habit, children who took their baths in the river were 13.1 times more likely to test positive than those who took their baths at home $(C O R=13.10, p$-value $=0.039)$. Children who trimmed their nails more than once in a week were $74 \%$ less likely to test positive than those who trimmed their nails once in a week (COR = $0.26, \mathrm{p}$-value $=0.019$ ). 
Table 3

Factors associated with test positivity for $\mathrm{G}$. lamblia

\begin{tabular}{|c|c|c|c|c|c|c|}
\hline Characteristics & $\begin{array}{l}\text { Negative No. } \\
(\%)\end{array}$ & $\begin{array}{l}\text { Positive No. } \\
\text { (\%) }\end{array}$ & $\begin{array}{l}\text { Crude OR } \\
(95 \% \mathrm{Cl})\end{array}$ & $\begin{array}{l}P \\
\text { value }\end{array}$ & AOR & $P$ \\
\hline \multicolumn{7}{|l|}{ Gender } \\
\hline Male & $63(84.0)$ & $12(16.0)$ & $\begin{array}{l}1.46(0.60 \\
3.51)\end{array}$ & 0.404 & & \\
\hline Female & $84(88.4)$ & $11(11.6)$ & 1 & & & \\
\hline \multicolumn{7}{|l|}{ Age } \\
\hline $6-9$ & $30(78.9)$ & $8(21.1)$ & 1 & & 1 & \\
\hline More than 10 & $117(88.6)$ & $15(11.4)$ & $\begin{array}{l}0.48(0.19 \\
1.24)\end{array}$ & 0.130 & $\begin{array}{l}0.33(0.12 \\
0.93)\end{array}$ & 0.035 \\
\hline \multicolumn{7}{|c|}{ Distance of residence from water source } \\
\hline$<1 \mathrm{Km}$ & $47(82.5)$ & $10(17.5)$ & 1 & & & \\
\hline$>1 \mathrm{Km}$ & $100(88.5)$ & $13(11.5)$ & $\begin{array}{l}0.61(0.25 \\
1.50)\end{array}$ & 0.280 & & \\
\hline \multicolumn{7}{|c|}{ Source of Drinking water } \\
\hline $\begin{array}{l}\text { Ground/Pure } \\
\text { Water }\end{array}$ & $7(77.8)$ & $2(22.2)$ & 1 & & & \\
\hline Tap water & $140(87.0)$ & $21(13.0)$ & $\begin{array}{l}0.53(0.10 \\
2.70)\end{array}$ & 0.440 & & \\
\hline \multicolumn{7}{|l|}{ Type of latrine } \\
\hline $\begin{array}{l}\text { Non Sanitary } \\
\text { Latrine }\end{array}$ & $92(87.6)$ & $13(12.4)$ & $\begin{array}{l}0.78(0.32 \\
1.90)\end{array}$ & 0.579 & & \\
\hline Sanitary latrine & $55(84.6)$ & $10(15.4)$ & 1 & & & \\
\hline \multicolumn{7}{|c|}{ Hand washing before meals } \\
\hline No & $94(86.2)$ & $15(13.8)$ & 1 & & & \\
\hline Yes & $53(86.9)$ & $8(13.1)$ & $\begin{array}{l}0.95(0.38 \\
2.38)\end{array}$ & 0.906 & & \\
\hline \multicolumn{7}{|c|}{ Habit of washing vegetables and fruits } \\
\hline No & $8(88.9)$ & $1(11.1)$ & $\begin{array}{l}0.79(0.09 \\
6.63)\end{array}$ & 0.828 & & \\
\hline Yes & $139(86.3)$ & $22(13.7)$ & 1 & & & \\
\hline
\end{tabular}




\begin{tabular}{|c|c|c|c|c|c|c|}
\hline Characteristics & $\begin{array}{l}\text { Negative No. } \\
(\%)\end{array}$ & $\begin{array}{l}\text { Positive No. } \\
\text { (\%) }\end{array}$ & $\begin{array}{l}\text { Crude OR } \\
(95 \% \mathrm{Cl})\end{array}$ & $\begin{array}{l}P \\
\text { value }\end{array}$ & AOR & $P$ \\
\hline In the house & $55(87.3)$ & $8(12.7)$ & 1 & & & \\
\hline In the school & $92(86.0)$ & $15(14.0)$ & $\begin{array}{l}1.12(0.45 \\
2.82)\end{array}$ & 0.808 & & \\
\hline \multicolumn{7}{|c|}{ Frequency of Trimming finger nail } \\
\hline Once a week & $81(81.0)$ & $19(19.0)$ & 1 & & 1 & \\
\hline $\begin{array}{l}\text { More than once a } \\
\text { week }\end{array}$ & $66(94.3)$ & $4(5.7)$ & $\begin{array}{l}0.26(0.08, \\
0.90)\end{array}$ & 0.019 & $\begin{array}{l}0.20(0.06, \\
0.66)\end{array}$ & 0.008 \\
\hline
\end{tabular}

In the multiple logistic regression analysis, two variables were selected and run using the enter method (age and frequency of trimming). Children aged more than 10 years were $67 \%$ less likely to be diagnosed positive for $G$. lamblia than those aged $6-9$ years $(A O R=0.33$, $p$-value $=0.035)$. The children who trimmed theirs nails more than once in a week were $80 \%$ less likely to be diagnosed positive for $G$. lamblia than those who trimmed their nails once in a week $(A O R=0.20, p$-value $=0.008)$.

Children who trimmed their nails every two weeks were $91 \%$ less likely to be diagnosed positive than those who trimmed their nails every week $(A O R=0.09$, $p$-value $=0.027)$. Children who trimmed their nails every three weeks were $79 \%$ less likely to test positive than those who trimmed their nails every week $(A O R=0.21, p$-value $=0.158)$. Children who trimmed their nails every month were $57 \%$ less likely to test positive than those who trimmed their nails every week $(A O R=0.43, p$-value $=0.315)$ (data not shown).

There was no significant interaction between the age and frequency of nail trimming ( $p$-value $=0.376)$. No multicollinearity for all the variables $(\mathrm{VIF}<10)$ was observed. The assumption for the Hosmer and Lemeshow test was satisfied ( $p$-value $=0.663$ ), indicating adequate model fitness with the two variables. The area under the ROC curve (AUC) was $68.5 \%$, indicating the sufficient discriminant ability of the final model with age and frequency of nail trimming.

\section{Discussion}

Epidemiological information that confirms the spread of intestinal parasitic infections is a prerequisite in the design and implementation of appropriate prevention and control strategies. This study was conducted to determine the prevalence of two gastrointestinal parasites, i.e. E. histolytica and G. lamblia, and the associated risk factors among schoolchildren in Um-Asher area, South Khartoum, Sudan.

The overall prevalence of the two parasites among the 170 children was 20\% (34 of 170), with 13 children infected with E. histolytica (7.6\%) and 23 with G. lamblia (13.5\%). Mixed infections with G. lamblia and $E$. histolytica were detected in $1.2 \%$ (2 of 170) of the children. G. lamblia was remarkably more frequent among the children than E. histolytica. This finding is consistent with the results of previous studies 
conducted in different parts of Sudan and globally. The predominance of G. lamblia over E. histolytica was also identified in a study conducted by Suliman et al. (11), Siddig et al. (12) and Gabbad and Elawad (13). Similar infection patterns were reported from other countries, such as Ethiopia (14), Nepal (15) and Iran (16).

The proportion of children infected with E. histolytica was higher than those infected with G. lamblia, similar to the report of a study conducted in the same geographical area (17) and in Côte d'Ivoire, Iraqi and Ethiopia $(5,18,19)$. The discrepancy in prevalence and predominance of the two parasites among studies conducted inside or outside the country may be due to several factors, including climatic conditions, poverty level, nutritional status, socio-economic conditions, high population density, healthrelated behaviour, illiteracy and poor sanitation (20).

The infection with E. histolytica and G. lamblia was not significantly associated with gender $(p>0.05)$. However, males were 3.1 and 1.5 times more likely to test positive for E. histolytica and G. lamblia than females, respectively ( $C O R=3.10$ and 1.46$)$. This finding is in agreement with other reports that showed that more males were infected with both parasites $(18,21,22)$. The majority of the positive cases were also reported in females, who also had higher odds of being infected with E. histolytica and G. Iamblia (4). Other studies reported slight gender differences (1), while a significant association with boys being more infected than girls were also reported (23). These findings indicate that the possibility of being infected with both parasites might be related to gender-specific behaviour within a community. However, males are more exposed to outdoor activities, which make them more vulnerable to intestinal parasitic infections, whereas females mostly remain indoors.

This study revealed no significant differences in the prevalence of E. histolytica and G. lamblia associated with age. However, a relatively higher infection rate was found in children aged more than 10. These children were 1.6 times more likely to test positive for $E$. histolytica than those from the 6-9 years group. For $G$. lamblia, children in the same age were $52 \%$ less likely to be diagnosed positive than those aged $6-9$ years $(\mathrm{COR}=0.48$, $\mathrm{p}$-value $=0.130)$. This finding could be attributed to the common pattern of children behaviour, that is, their outdoor activities increase as they grow older, thereby increasing their exposure to intestinal parasites.

In conclusion: Urgent actions, i.e. long-term control measures and improvement of personal hygienic practices and sanitary and living conditions, must be implemented.

\section{Limitations}

The major limitation of this study was the small sample size. Therefore, the estimated prevalence cannot reflect the burden of the disease across the study area.

\section{List Of Abbreviations}


E.: Entamoeba, G: Giardia, ROC: Receiver Operating Characteristics, COR: Crude Odds Ratio, AOR: Adjusted Odds Ratio, AUC: Area under the ROC Curve

\section{Declarations}

\section{Ethics approval and consent to participate}

The study was conducted after the approval of the project by the ethical review committee of the Research Directorate, Federal Ministry of Health ( $\mathrm{fmoh} / \mathrm{nhrc} / \mathrm{rd} / \mathrm{rec}$ ). Verbal consent was obtained from the heads of the target schools. The children were involved in the study after informed written consent was obtained from the parents or guardians and assent from all participating children.

\section{Consent for publication}

Not applicable.

\section{Availability of data and material}

All original or analyzed data for this study is available on request from the corresponding author.

\section{Competing interests}

The authors declare that they have no competing interests.

\section{Funding}

This study was supported by the Grants of the Commission of Scientific Research and Innovation, Ministry of Higher Education and Scientific Research, Sudan, grant No. SRIC/2017/RP761.

\section{Authors' contributions}

$\mathrm{KH}, \mathrm{AMM}, \mathrm{MJ}$ and ZM: Conceived and designed the study, TA, ZMS, HAE, EE and EN: field and laboratory work, AS: Statistical analysis. All authors read and approved the final manuscript.

\section{Acknowledgements}

The authors would like to thank school's directors and all study participants for their contribution in success of this work.

\section{Author details}

${ }^{1}$ Department of Zoology, Faculty of Science and Technology, Omdurman Islamic University, B.0.Box382, Omdurman, Sudan 
${ }^{2}$ Department of Medical Microbiology \& Parasitology, School of Medical Sciences, Universiti Sains Malaysia, 16150 Kubang Kerian, Kelantan, Malaysia

${ }^{3}$ Weaad Medical Center, Khartoum, Sudan

${ }^{4}$ Unit of Biostatistic and Reseach Methodology, School of Medical Sciences, Universiti Sains Malaysia, 16150 Kubang Kerian, Kelantan, Malaysia

\section{References}

1. Wegayehu T, Tsalla T, Seifu B, Teklu T. Prevalence of intestinal parasitic infections among highland and lowland dwellers in Gamo area, South Ethiopia. BMC Public Health 2013;13,151.

2. Hamad M, Mokhtar A, Alameldin M. Prevalence of intestinal parasitic infections among school aged children in Berber locality, River Nile State, Sudan 2017. J Microbiol Exp 2019;7, 85-6.

3. Hajissa K, Abd Elhafiz M, Eshag HA, Alfadel A, Nahied E, Dahab R, et al. Prevalence of schistosomiasis and associated risk factors among school children in Um-Asher Area, Khartoum, Sudan. BMC Res Notes 2018;11, 779.

4. Speich B, Marti H, Ame SM, Ali SM, Bogoch II, Utzinger J, et al. Prevalence of intestinal protozoa infection among school-aged children on Pemba Island, Tanzania, and effect of single-dose albendazole, nitazoxanide and albendazole-nitazoxanide. Parasit Vectors 2013, 6, 3.

5. Ouattara M, N'Guéssan NA, Yapi A, N'Goran EK. Prevalence and spatial distribution of Entamoeba histolytica/dispar and Giardia lamblia among schoolchildren in Agboville area (Côte d'Ivoire). PLoS Negl Trop Dis 2010, 4, e574.

6. Bazzaz AA, Shakir OM, Alabbasy RH. Prevalence of two gastrointestinal parasites Entamoeba histolytica and Giardia lamblia within Samarra city, Iraq. Advances in Biosci and Biotechnol 2017, 8, 399.

7. Homan WL, Mank TG. Human giardiasis: genotype linked differences in clinical symptomatology. Int J Parasito/ 2001, 31, 822-6.

8. Fekadu S, Taye K, Teshome W, Asnake S. Prevalence of parasitic infections in HIV-positive patients in southern Ethiopia: a cross-sectional study. J Infect Dev Ctries 2013, 7, 868-72.

9. Mane M, Kadu A, Mumbre S, Deshpande M, Gangurde N. Prevalence of intestinal parasitic infections and associated risk factors among pre-school children in tribal villages of North Maharashtra, India. Int J Res Health Sci 2014, 2,133-9.

10. Mekonnen HS, Ekubagewargies DT. Prevalence and factors associated with intestinal parasites among under-five children attending Woreta Health Center, Northwest Ethiopia. BMC Infect Dis 2019, $19,256$.

11. Suliman M, Magboul A, Mohammed H, Tamomh A, Bakhit H. Prevalence of Intestinal Parasitic Infections and Associated Risk Factors among School Children in White Nile State, Sudan. J Infect Dis Diagn 2019, 4, 2. 
12. Siddig HS, Mohammed IA, Mohammed MN, Bashir AM. Prevalence of intestinal parasites among selected group of primary school children in Alhag Yousif Area, Khartoum, Sudan. Int J Med Res Health Sci 2017, 6, 125-31.

13. Gabbad AA, Elawad MA. Prevalence of intestinal parasite infection in primary school children in Elengaz area, Khartoum, Sudan. Academic Research International 2014, 5, 86.

14. Sitotaw B, Mekuriaw H, Damtie D. Prevalence of intestinal parasitic infections and associated risk factors among Jawi primary school children, Jawi town, north-west Ethiopia. BMC Infect Dis 2019, $19,341$.

15. Sah RB, Bhattarai S, Yadav S, Baral R, Jha N, Pokharel PK. A study of prevalence of intestinal parasites and associated risk factors among the school children of Itahari, Eastern Region of Nepal. Trop Parasitol 2013, 3, 140.

16. Saki J, Amraee D. Prevalence of intestinal parasites among the rural primary school students in the west of Ahvaz county, Iran, 2015. Jentashapir Journal of Health Research 2017, 8.

17. Muhajir A, Hajissa K, Mohamed Z, Aal A. Prevalence of Intestinal Parasitic Infection among Children in Al-kalakla, Khartoum, Sudan. World App/ Sci J 2017, 35, 219-22.

18. Al Saqur IM, Al-Warid HS, Albahadely HS. The prevalence of Giardia lamblia and Entamoeba histolytica/dispar among Iraqi provinces. Karbala International Journal of Modern Science 2017, 3, 93-6.

19. Maru DS. Prevalence of intestinal parasitic infections and associated risk factors among school children in Adigrat town, northern Ethiopia. International Journal of Emerging Trends in Science and Technology 2015, 4, 4943-8.

20. Shakya B, Shrestha S, Madhikarmi N, Adhikari R. Intestinal parasitic infection among school children. J Nepal Health Res Counc, 2012.

21. Khan W, Noor-un-Nisa KA. Prevalence and risk factors associated with intestinal parasitic infections among food handlers of Swat, Khyber Pakhtunkhwa. Pakistan J Food Nutr Res 2017, 5, 331-6.

22. Tigabu A, Taye S, Aynalem M, Adane K. Prevalence and associated factors of intestinal parasitic infections among patients attending Shahura Health Center, Northwest Ethiopia. BMC Res Notes 2019, 12, 333.

23. ESalem RMA, Gahgah SAA, Ali ASH, Al Shrief SAR. Prevalence and risk factors associated with Entamoeba Histolytica infection among children in Sebha, Libya. Dentistry and Medical Research 2017, 5, 48. 